\title{
The association between Cardiovascular Diseases and Its risk factors in Levels of Smoking: Results of a Prospective Study on Ravansar Non-Communicable Diseases
}

\author{
Behrooz Hamzeh \\ Kermanshah University of Medical Sciences \\ Roya Safari Faramani \\ Kermanshah University of Medical Sciences \\ Farid Najafi \\ Kermanshah University of Medical Sciences \\ Yahya Pasdar \\ Kermanshah University of Medical Sciences

\section{Ebrahim Shakiba} \\ Kermanshah University of Medical Sciences \\ Mitra Darbandi ( $\square$ m.darbandi@kums.ac.ir) \\ Kermanshah University of Medical Sciences https://orcid.org/0000-0002-9173-8814
}

\section{Research article}

Keywords: cardiovascular diseases, smoking, diabetes, hypertension

Posted Date: January 16th, 2020

DOI: https://doi.org/10.21203/rs.2.21055/v1

License: (c) (i) This work is licensed under a Creative Commons Attribution 4.0 International License. Read Full License 


\section{Abstract}

Background: smoking is a strong confounder associated with cardiovascular diseases (CVD) and many of the associated risk factors. This study aims to investigate the association between the risk factors of CVD across different level of smoking including former smoker, current smoker and never smokers.

Methods: This is a cross-sectional analysis of the first phase data from the Prospective Study of Non-Communicable Diseases in Ravansar (RaNCD), on 10063 adults aged 35 to 65. The smoking status was divided into three groups of current smokers, former smokers, and never smokers, and the smoking intensity was categorized into light, moderate, and heavy. Individuals with a history of myocardial infarction, cardiac arrest, and coronary artery diseases, or those who took CVD medications were considered as a cardiovascular patient. Covariates were identifies via Logistic regression.

Findings: CVD odds in 50-65 age group in current smokers 2.75 times $(1.62-4.67: 95 \% \mathrm{Cl})$ the $35-49$ age group, in former smokers $1.74(1.04-$ $2.90: 95 \% \mathrm{Cl})$ and in never smokers $2.16(1.83-2.56: 95 \% \mathrm{Cl})$. In women, CVD odds was greater compared to men in current smokers and never smokers. In current smokers, hypertension, diabetes, and dyslipidemia, increased the odds of $C V D$ by $O R=7.87-P<0.0001, O R=1.47-P=0.23$, and $O R=1.81-P<0.0001$, respectively. In former smokers, hypertension ( $O R=14.15, P<0.0001)$ and diabetes $(O R=2.74, P=0.0001)$ significantly increased the odds of CVD. On the other hand, vigorous physical activity in former smokers was a protective factor against CVD (OR $=0.53$, $P<0.0001)$. In heavy smokers, odds of CVD was higher by $O R=1.97-P<0.0001$ for those with overweight or obesity.

Conclusion: Smoking was significantly association with the risk factors of CVD and the association between smoking and the risk factors of CVD was significantly differ across different levels of smoking.

\section{Introduction}

Cardiovascular diseases (CVD) are one of the world's leading causes of mortality, imposing considerable economic and social costs on societies. According to the World Health Organization, CVD have been one of the leading causes of mortality in the past 15 years, been introduced as the world's leading cause of mortality as of 2016. The latest Global Burden of Disease study has estimated that in 2016, CVD has brought about the deaths of 17.6 people across the globe, an approximate rise of $14 \%$ compared to $2006(1,2)$. Similar to most Western Asian countries, CVD is the leading cause of mortality in Iran, responsible for $\% 46$ of all the deaths in 2015. What's more, prevalence of CVD risk factors is high in West Asia, including Iran. The average cholesterol level and body mass index (BMI), as two important risk factors, in both sexes, and hypertension in Iranian women, are higher than the world's average (3).

Owing to the significance of CVD, identification of its potential risk factors can mitigate its prevalence and the social burden induced by it. Numerous CVD risk factors are recognized, most important of which is hypertension, lipid disorders, family history, obesity, and unhealthy lifestyle, entailing physical inactivity and smoking (4-6).

The significance of smoking as the most important risk factor of many chronic diseases, like CVD, is undoubtable $(3,7)$. Numerous crosssectional studies, including a prospective study on Chinese men has shown that smoking is a potential CVD risk factor, which combined with hypertension, can increase the risk of CVD $(2,8,9)$. The data analysis obtained from three prospective studies in Japan shows that quitting smoking - regardless of the smoking period or cigarettes per day - reduced the risk of CVD-induced mortality (10). Moreover, the prevalence of smoking, along with other risk factors, is on the rise in Iran (11). As reported by a nation-wide study on Iranian adults, the prevalence of smoking in Iran is $12.5 \%$ (23.4\% in men and $1.4 \%$ in women), with an average 13.7 cigarettes per day (12). The findings of a meta-analysis in 2013 maintain that one fifth of Iranian men and 2 to $3 \%$ of women have a daily habit of smoking, which significantly rises from age 30 (11). From a different viewpoint, when dealing with the problems associated with smoking in societies, the adverse effects of smoking is considerable on the health systems and societies in general, using up 1.5 to $6.8 \%$ of the national healthcare budget and 0.22 to $0.88 \%$ of the gross domestic product, annually (13).

The study by Jibin Tan et al. showed that CVD risk in smokers with hypertension was higher than non-smokers(2). The effect size of other CVD risk factors can be affected when accompanied across different levels of smoking (former, current and never smokers), or even the subgroups associated with the intensity of abuse (light, moderate and heavy smokers). Furthermore, CVD risk factors may have different impacts in different societies and especially across different ethnicities and races. The present study is one of the first studies carried out on a considerable population of Iranian Kurds. First, we hypothesized that cigarette smoking would be significantly correlated with the risk factors of CVD. Second, we hypothesized that the association between cigarette smoking and the risk factors of CVD would significantly differ across different levels of smoking.

\section{Methods}




\section{Study Population}

This is a cross-sectional analysis of the first phase data from the Prospective Study of Non-Communicable Diseases in Ravansar (RaNCD), as part of the Prospective Epidemiological Research in Iran (PERSIAN) currently being carried out on different ethnic groups, by the coordination of Iranian Ministry of Health and Medical Education, with the full description and methods printed elsewhere (14). Ravansar is a city in Kermanshah province. With a population of roughly 50 thousand, Ravansar is a Kurdish city in Kermanshah. Uniformity in terms of ethnic diversity, ease of access, and relative stability of population in terms of migration, were the major reasons for selecting the city, as one of the Persian cohort sites in Iran. A more detailed version of RaNCD has already been published (15).

The RaNCD inclusion criteria included the age range of 35-65 years, being a permanent resident of Ravansar region (the town of Ravansar and all the adjacent villages), being an Iranian national, and consent to participate. All the participants of Ravansar cohort study, a total of 10063 individuals, entered this study. The exclusion criteria were unwillingness to participate, living in Ravansar less than 9 months per year, new residents of the region (less than one year), those who were unable to refer to prospective studies center in Ravansar, those with mental disorders, physical disabilities, blindness, deafness, amnesia or any acute psychological disorder which rendered communication and interview impossible.

\section{Data Collection Instrument}

Before the study begins, trained interviewers went door to door to both introduce the study and invite eligible individuals to participate. One day prior to the interview, the participants were contacted and reminded of their appointments. All the interviews were conducted by trained individuals at the study-specific clinic location.

The participants' demographic data like age, sex, marital status, years of education, place of residence (urban/rural), and narcotics and alcohol use, was registered online on specifically-designed electronic data collection forms.

Questionnaires were used to evaluate the smoking status. The participants were categorized into three groups of current smokers, former smokers, and never smokers. The participants recognized as current smokers, smoked 1 to 100 cigarettes per day. Participants who did not smoke regularly or for some time during the past year, yet had smoked more than 100 cigarettes in their life, were classified as former smokers. Never smokers were defined as those who never smoked or had smoked less than 100 cigarettes in their life. In terms of the number of cigarettes per day, the current smokers were further divided into light smokers ( 1 to 9 cigarettes a day), moderate smokers (10 to 19 cigarettes a day), and heavy smokers (20 cigarettes or more a day).

The socio-economic status of the participants entailed a combination of economic welfare, education, and place of residence. As for education, the participants were divided into 5 groups according to the years of education. In terms of the place of residence, the individuals were divided to the two groups of urban and rural residents. Last but not least, the variable of socio-economic status was created through a combination of the said variables (welfare, education, and place of residence) and divided the participants into five groups.

In order to investigate the physical activity of the participants, the physical activity questionnaire designed for the PERSIAN cohort study was employed. Said questionnaire included 22 questions targeting different daily activities of individuals around-the-clock, the answers to which were recorded by hour or minute per day. The questionnaire's data was eventually extracted as met/hour per day and utilized.

Individuals with a fasting blood sugar of equal to or higher than $126 \mathrm{mg} / \mathrm{dL}$, or those taking blood sugar lowering medication were diagnosed with Type 2 Diabetes. Participants with a systolic value of equal to or higher than 140 and a diastolic value of $90 \mathrm{mmHg}$, or those taking blood pressure lowering medication were diagnosed with hypertension.

Blood lipid disorders, in the present study, was defined as disorders in the serum levels of lipid profile indicators, including one or more of the following items: $L D L>130 \mathrm{mg} / \mathrm{dl}, \mathrm{HDL}<45 \mathrm{mg} / \mathrm{dl}, \mathrm{TG}>200 \mathrm{mg} / \mathrm{dl}$, Total Cholesterol $>200 \mathrm{mg} / \mathrm{dl}$, or taking lipid-lowering medication, like Amlodipine, Atherostatin, Clofibrate, Fenofibrate, Gemfibrozil, Lovastatin and Simvastatin.

Individuals with a record of hospitalization or treatment for one or more cardiovascular disease, like cardiac arrest, myocardial infarction, and coronary artery disease, or otherwise took CVD medication, were considered as having a cardiovascular disease, following RaNCD protocol.

Identical to the protocol of Ravansar prospective study, the participants signed an informed consent.

\section{Data Analysis}

Pursuant to the study objectives, the data analysis was carried out using Stata 14.2 (StataCorp, College Station, TX, USA). The CVD prevalence with a $95 \%$ Confidence Interval in all the study groups was presented in terms of smoking and for the different levels of 
independent variables. To investigate the factors affecting CVD, and considering the binomial distribution of the study outcome (presence or absence of CVD), logistic regression was employed to offer the odds ratio. P values less than 0.05 were considered significant.

\section{Findings}

The present study was conducted on 10063 participants aged $48.10 \pm 8.25$, comprising $4773(47.43 \%)$ males, $8026(80 \%)$ never smokers, $1178(11.74 \%)$ current smokers, and $829(8.26 \%)$ former smokers. Nearly half the smokers $(48.80 \%)$ were heavy smokers and roughly a third of the participants $(33.90 \%)$ were light smokers, smoking 1 to 9 cigarettes a day.

Among former smokers, CVD prevalence was greater in the 50-65 age group compared to the $35-49$ age group (16.5\% vs. $5.8 \%$ ). CVD prevalence in current smokers of both age groups was higher than that of former smokers.

For all three smoking statuses, CVD prevalence was greater in individuals with low physical activity, rather than those with moderate or vigorous physical activity. CVD prevalence of individuals with a BMI of more than 25 was higher than those with a BMI of less than $25 \mathrm{~kg} / \mathrm{m}^{2}$, in all the three smoking statuses. In current smokers, CVD prevalence was $33 \%$ for diabetic and $18 \%$ for non-diabetic participants. In former smokers as well, CVD prevalence was higher in diabetic rather than non-diabetic participants (Table 1).

Adjusted regression model shown, CVD odds in 50-65 age group in current smokers 2.75 times $(1.62-4.67: 95 \% \mathrm{Cl})$ the $35-49$ age group, in former smokers $1.74(1.04-2.90: 95 \% \mathrm{Cl})$ and in never smokers $2.16(1.83-2.56: 95 \% \mathrm{Cl})$. In women, CVD odds was greater compared to men in current smokers and never smokers. Hypertension, diabetes, and lipid disorders increase CVD odds in current smokers by 7.87 (5.17-11.98: $95 \% \mathrm{Cl}), 1.47(0.85-2.55: 95 \% \mathrm{Cl})$, and $1.81(1.18-2.78)$, respectively. Among former smokers, hypertension and diabetes increased the CVD odds by $14.15(8.69-23.03: 95 \% \mathrm{Cl})$ and $2.74(1.39-5.39: 95 \% \mathrm{Cl})$.

In current smokers, obesity and overweight (BMI $\geq 25)$ increased the CVD odds. Vigorous physical activity in former smokers was a protective factor against CVD by $0.53(0.28-0.97: 95 \% \mathrm{Cl})$. However, for current smokers, the protective function of physical activity was not significant. The odds ratios of non-smokers show that factors like being female, older age, hypertension, diabetes, and lipid disorders, per se, regardless of the smoking effects, increased CVD odds (Table 2).

Table 3 shows the odds ratio for a risk of CVD in current smokers based on smoking intensity. The CVD odds in 50-65 year-old individuals with $\leq 20$ cigarettes a day was 2.41 times $(1.52-3.87: 95 \% \mathrm{Cl})$ the $35-49$ year-olds. In heavy smokers, risk of CVD was 1.97 times greater (1.183.28: $95 \% \mathrm{Cl}$ ) in those with overweight or obesity (BMI $\geq 25)$. As for light and moderate smokers, odds ratio of CVD risk factors in the group with a BMI of $\geq 25$ was higher than those with normal weight, which was not significant.

Table 1 - Frequency and prevalence of cardiovascular diseases in the subgroups of smoking

Table 2 - Adjusted Regression Model to Calculate the Odds Ratio of Cardiovascular Diseases 


\begin{tabular}{|c|c|c|c|c|c|c|c|c|}
\hline \multirow[t]{2}{*}{ Variables } & \multirow[t]{2}{*}{ Categories } & \multicolumn{2}{|c|}{ Never smoker } & \multicolumn{2}{|c|}{ Former smoker } & \multicolumn{2}{|c|}{ Current smoker } & \multirow{2}{*}{$\begin{array}{l}\text { Total } \\
\text { Prevalence } \\
\text { (CI95\%) }\end{array}$} \\
\hline & & n (\%) & $\begin{array}{c}\text { Prevalence } \\
\text { (CI 95\%) }\end{array}$ & n (\%) & $\begin{array}{c}\text { Prevalence } \\
\text { (CI 95\%) }\end{array}$ & n (\%) & $\begin{array}{c}\text { Prevalence } \\
\text { (CI95\%) }\end{array}$ & \\
\hline \multirow[t]{2}{*}{ Gender } & Men & $3026(63.6)$ & $\begin{array}{c}9.2(8.2- \\
10.2) \\
\end{array}$ & $660(13.9)$ & $\begin{array}{c}8.8(7.0- \\
10.3) \\
\end{array}$ & $1071(22.5)$ & $\begin{array}{c}16.6(14.0- \\
19.7) \\
\end{array}$ & $\begin{array}{c}10.1(9.2- \\
10.9) \\
\end{array}$ \\
\hline & Women & $5000(94.8)$ & $\begin{array}{c}16.0(15.0- \\
10.2)\end{array}$ & 169(3.2) & $\begin{array}{c}30.8(2.3- \\
4.1)\end{array}$ & $107(2.1)$ & $\begin{array}{c}31.9(25.3- \\
39.3)\end{array}$ & $\begin{array}{c}16.8(15.8- \\
17.9)\end{array}$ \\
\hline \multirow[t]{2}{*}{ Age group } & $35-49$ & 4999(30.6) & $\begin{array}{c}6.6(5.9- \\
7.3)\end{array}$ & 298(5.1) & $\begin{array}{c}5.8(4.2- \\
7.8)\end{array}$ & $657(11.1)$ & $\begin{array}{c}8.4(5.7- \\
12.1)\end{array}$ & $\begin{array}{c}6.6(5.9- \\
7.2)\end{array}$ \\
\hline & $50-65$ & $3027(74.2)$ & $\begin{array}{c}24.7(23.2- \\
26.7)\end{array}$ & $531(13.1)$ & $\begin{array}{c}16.5(13.5- \\
19.9)\end{array}$ & $521(12.8)$ & $\begin{array}{c}26.2(22.6- \\
30.1)\end{array}$ & $\begin{array}{c}23.8(22.5- \\
25.1)\end{array}$ \\
\hline \multirow[t]{2}{*}{ Location } & Rural & $3191(77.9)$ & $\begin{array}{c}13.5(12.4- \\
14.7)\end{array}$ & $354(8.6)$ & $\begin{array}{c}8.8(6.7- \\
11.4)\end{array}$ & $547(13.4)$ & $\begin{array}{c}18.4(7.0- \\
10.3)\end{array}$ & $\begin{array}{c}13.8(12.9- \\
14.7)\end{array}$ \\
\hline & Urban & $4835(88.4)$ & $\begin{array}{c}13.4(12.4- \\
14.4)\end{array}$ & $475(8.0)$ & $\begin{array}{c}12.1(9.7- \\
14.8)\end{array}$ & $631(10.6)$ & $\begin{array}{c}20.8(17.4- \\
24.7)\end{array}$ & $\begin{array}{c}13.3(12.3- \\
14.4)\end{array}$ \\
\hline \multirow[t]{2}{*}{ Marital status } & Married & $7148(79.0)$ & $\begin{array}{c}13.5(12.8- \\
14.3)\end{array}$ & $785(8.7)$ & $\begin{array}{c}10.3(8.6- \\
12.2)\end{array}$ & 1115(12.3) & $\begin{array}{c}18.9(16.4- \\
21.9)\end{array}$ & $\begin{array}{c}13.6(12.9- \\
14.3)\end{array}$ \\
\hline & Single/widow & $878(89.1)$ & $\begin{array}{c}12.5(10.5- \\
14.9)\end{array}$ & $44(4.5)$ & $\begin{array}{c}14.3(7.5- \\
25.3)\end{array}$ & $63(6.4)$ & $\begin{array}{c}34.1(21.6- \\
49.3)\end{array}$ & $\begin{array}{c}13.7(11.7- \\
16.1)\end{array}$ \\
\hline \multirow[t]{2}{*}{$\begin{array}{l}\text { Alcohol } \\
\text { consumption }\end{array}$} & Yes & $244(38.4)$ & $\begin{array}{c}10.6(7.3- \\
15.2)\end{array}$ & 124(19.5) & $\begin{array}{c}7.9(5.2- \\
11.7)\end{array}$ & $114(87.8)$ & $\begin{array}{c}16.1(10.6- \\
23.7)\end{array}$ & $\begin{array}{c}13.8(13.1- \\
14.5)\end{array}$ \\
\hline & No & $7782(82.8)$ & $\begin{array}{c}13.5(12.7- \\
14.2)\end{array}$ & $124(19.5)$ & $\begin{array}{c}11.3(9.4- \\
13.5)\end{array}$ & $267(42.1)$ & $\begin{array}{c}20.4(17.6- \\
23.5)\end{array}$ & $\begin{array}{c}10.5(8.4- \\
13.2)\end{array}$ \\
\hline \multirow[t]{2}{*}{$\begin{array}{l}\text { Body mass } \\
\text { index }\end{array}$} & $<25 \mathrm{~kg} \cdot \mathrm{m}^{2}$ & $2192(73.9)$ & $\begin{array}{c}9.8(8.6- \\
11.1)\end{array}$ & $254(8.6)$ & $\begin{array}{c}7.3(5.3- \\
9.9)\end{array}$ & $517(17.4)$ & $\begin{array}{c}11.0(7.7- \\
15.5)\end{array}$ & $\begin{array}{c}9.5(8.5- \\
10.6)\end{array}$ \\
\hline & $\geq 25 \mathrm{~kg} \cdot \mathrm{m}^{2}$ & $5780(82.7)$ & $\begin{array}{c}14.7(13.8- \\
15.6)\end{array}$ & $564(8.1)$ & $\begin{array}{c}12.4(10.1- \\
15.81)\end{array}$ & $645(9.2)$ & $\begin{array}{c}23.7(20.4- \\
27.4)\end{array}$ & $\begin{array}{c}15.2(14.4- \\
16.1)\end{array}$ \\
\hline \multirow[t]{2}{*}{ Calorie intake } & $\begin{array}{l}<2500 \text { kcal } \\
\text { per day }\end{array}$ & $2199(86.7)$ & $\begin{array}{c}18.3(16.7- \\
19.9)\end{array}$ & 153(6.1) & $\begin{array}{c}16.8(12.1- \\
22.9)\end{array}$ & $184(7.3)$ & $\begin{array}{c}31.3(24.5- \\
39.2)\end{array}$ & $\begin{array}{c}19.0(17.5- \\
20.6)\end{array}$ \\
\hline & $\begin{array}{l}\geq 2500 \mathrm{kcal} \\
\text { per day }\end{array}$ & $5803(77.7)$ & $\begin{array}{c}11.6(10.8- \\
12.4) \\
\end{array}$ & 675(9.1) & $\begin{array}{c}9.2(7.6- \\
11.2) \\
\end{array}$ & $991(13.4)$ & $\begin{array}{l}\text { 17.1(14.4- } \\
20.1)\end{array}$ & $\begin{array}{c}11.8(11.1- \\
12.5)\end{array}$ \\
\hline \multirow[t]{2}{*}{ Hypertension } & Yes & $1250(79.5)$ & $\begin{array}{c}54.8(52.0- \\
57.5)\end{array}$ & 193(12.3) & $\begin{array}{c}52.7(44.0- \\
61.2)\end{array}$ & $129(8.2)$ & $\begin{array}{c}53.3(46.2- \\
60.3)\end{array}$ & $\begin{array}{c}54.5(52.0- \\
56.9)\end{array}$ \\
\hline & No & $6760(80.1)$ & $\begin{array}{c}54.8(52.1- \\
57.5)\end{array}$ & 633(7.5) & $\begin{array}{c}52.7(44.1- \\
61.2)\end{array}$ & 1048(12.4) & $\begin{array}{c}53.4(46.3- \\
60.3)\end{array}$ & $\begin{array}{c}6.1(5.5- \\
6.5)\end{array}$ \\
\hline \multirow[t]{2}{*}{ Diabetes } & Yes & $626(76.6)$ & $\begin{array}{c}3.4(3.1- \\
3.7)\end{array}$ & $88(10.8)$ & $\begin{array}{c}29.5(20.9- \\
40.1)\end{array}$ & $103(12.6)$ & $\begin{array}{c}33.0(24.5- \\
42.6)\end{array}$ & $\begin{array}{c}33.2(30.1- \\
36.5)\end{array}$ \\
\hline & No & $7349(80.3)$ & $\begin{array}{c}11.7(11.1- \\
12.5)\end{array}$ & $1080(11.8)$ & $\begin{array}{c}9.1(7.5- \\
10.9)\end{array}$ & $723(7.9)$ & $\begin{array}{c}18.0(15.3- \\
20.9)\end{array}$ & $\begin{array}{c}11.9(11.3- \\
12.6)\end{array}$ \\
\hline \multirow[t]{2}{*}{ Hyperlipidemia } & Yes & $3340(75.6)$ & $\begin{array}{c}18.4(17.1- \\
19.7)\end{array}$ & 416(9.4) & $\begin{array}{c}12.6(10.3- \\
15.4)\end{array}$ & $664(15.1)$ & $\begin{array}{c}25.2(21.3- \\
29.6)\end{array}$ & $\begin{array}{c}18.2(17.1- \\
19.3)\end{array}$ \\
\hline & No & $4634(83.5)$ & $\begin{array}{c}9.9(9.8- \\
10.8)\end{array}$ & $410(7.4)$ & $\begin{array}{c}7.9(5.9- \\
10.7)\end{array}$ & $503(9.1)$ & $\begin{array}{c}14.4(11.3- \\
18.1)\end{array}$ & $\begin{array}{c}10.1(9.3- \\
19.3)\end{array}$ \\
\hline \multirow[t]{3}{*}{$\begin{array}{l}\text { Physical } \\
\text { activity }\end{array}$} & Low & $2129(77.1)$ & $\begin{array}{c}16.48(14.9- \\
18.12)\end{array}$ & $259(9.4)$ & $\begin{array}{c}13.90(10.7- \\
17.8)\end{array}$ & $374(13.5)$ & $\begin{array}{c}25.09(20.2- \\
30.7) \\
\end{array}$ & $\begin{array}{c}16.9(15.6- \\
18.4)\end{array}$ \\
\hline & Moderate & $4399(85.3)$ & $\begin{array}{c}13.43(12.4- \\
14.5)\end{array}$ & $337(6.5)$ & $\begin{array}{c}11.21(8.5- \\
14.6)\end{array}$ & $419(8.1)$ & $\begin{array}{c}20.5(16.5- \\
25.1)\end{array}$ & $\begin{array}{c}13.7(12.8- \\
14.7)\end{array}$ \\
\hline & Vigorous & $1494(70.8)$ & $\begin{array}{c}9.10(7.7- \\
10.7)\end{array}$ & $233(11.1)$ & $\begin{array}{c}6.51(4.4- \\
9.5)\end{array}$ & $384(18.2)$ & $\begin{array}{c}12.9(9.1- \\
17.8)\end{array}$ & $\begin{array}{c}9.1(7.9- \\
10.4)\end{array}$ \\
\hline
\end{tabular}




\begin{tabular}{|c|c|c|c|c|}
\hline \multirow[t]{2}{*}{ Variables } & \multirow[t]{2}{*}{ Categories } & Never smoker & Former smoker & Current smoker \\
\hline & & \multicolumn{3}{|c|}{ Odds Ratio (95\% CI) } \\
\hline \multirow[t]{2}{*}{ Gender } & Men & 1 & 1 & 1 \\
\hline & Women & $1.95(1.59-2.39)$ & $2.68(1.33-5.42)$ & $1.43(0.84-2.44)$ \\
\hline \multirow[t]{2}{*}{ Age group } & $35-49$ & 1 & 1 & 1 \\
\hline & $50-65$ & $2.16(1.83-2.56)$ & $1.74(1.04-2.90)$ & $2.75(1.62-4.67)$ \\
\hline \multirow[t]{5}{*}{ Socioeconomic Status } & Class 1 & 1 & 1 & 1 \\
\hline & Class 2 & $1.08(0.84-1.35)$ & $1.81(0.84-3.89)$ & $0.97(0.52-1.80)$ \\
\hline & Class 3 & $1.01(0.78-1.29)$ & $1.50(0.70-3.19)$ & $0.60(0.30-1.19)$ \\
\hline & Class 4 & $1.26(0.98-1.61)$ & $1.34(0.59-3.04)$ & $0.97(0.50-1.86)$ \\
\hline & Class 5 & $1.17(0.89-1.55)$ & $1.62(0.73-3.58)$ & $0.7(0.39-1.59)$ \\
\hline \multirow[t]{2}{*}{ Alcohol consumption } & No & 1 & 1 & 1 \\
\hline & Yes & $1.40(0.84-2.34)$ & $0.90(0.49-1.66)$ & $1.81(0.95-3.42)$ \\
\hline \multirow[t]{2}{*}{ Body mass index } & $<25 \mathrm{~kg} \cdot \mathrm{m}^{2}$ & 1 & 1 & 1 \\
\hline & $\geq 25 \mathrm{~kg} \cdot \mathrm{m}^{2}$ & $1.03(0.82-1.22)$ & $1.13(0.68-1.87)$ & $1.97(1.18-3.28)$ \\
\hline \multirow[t]{2}{*}{ Calorie intake } & $<2500$ kcal per day & 1 & 1 & 1 \\
\hline & $\geq 2500 \mathrm{kcal}$ per day & $0.89(0.74-1.06)$ & $0.86(0.46-1.59)$ & $0.68(0.41-1.13)$ \\
\hline \multirow[t]{3}{*}{ Physical activity } & Low & 1 & 1 & 1 \\
\hline & Moderate & $0.80(0.65-0.95)$ & $0.61(0.36-1.06)$ & $0.74(0.46-1.20)$ \\
\hline & Vigorous & $0.73(0.55-0.93)$ & $0.53(0.28-0.97)$ & $0.62(0.34-1.13)$ \\
\hline \multirow[t]{2}{*}{ Diabetes } & Yes & 1 & 1 & 1 \\
\hline & No & $1.89(1.50-2.38)$ & $2.74(1.39-5.39)$ & $1.47(0.85-2.55)$ \\
\hline \multirow[t]{2}{*}{ Hyperlipidemia } & Yes & 1 & 1 & 1 \\
\hline & No & $1.79(1.51-2.08)$ & $1.41(0.84-2.34)$ & $1.81(1.18-2.78)$ \\
\hline \multirow[t]{2}{*}{ Hypertension } & Yes & 1 & 1 & 1 \\
\hline & No & $13.86(11.76-16.33)$ & $14.15(8.69-23.03)$ & $7.87(5.17-11.98)$ \\
\hline
\end{tabular}

Table 3 - Adjusted regression model for calculating the odds ratio of cardiovascular diseases in current smokers

\begin{tabular}{|c|c|c|c|c|}
\hline \multirow[t]{3}{*}{ Variables } & \multirow[t]{3}{*}{ Categories } & \multicolumn{3}{|c|}{ No of cigarettes per day among current smokers } \\
\hline & & $1-9$ & $10-19$ & $\geq 20$ \\
\hline & & \multicolumn{3}{|c|}{ Odds Ratio (95\% CI) } \\
\hline \multirow{2}{*}{ Gender } & Men & 1 & 1 & 1 \\
\hline & Women & $4.99(2.42-10.26)$ & $2.81(0.77-9.60)$ & $0.84(0.37-1.89)$ \\
\hline \multirow[t]{2}{*}{ Age group } & $35-49$ & 1 & 1 & 1 \\
\hline & $50-65$ & $1.67(0.84-3.32)$ & $2.39(0.69-8.24)$ & $2.41(1.52-3.87)$ \\
\hline \multirow[t]{5}{*}{ Socioeconomic Status } & Class 1 & 1 & 1 & 1 \\
\hline & Class 2 & $1.35(0.59-3.85)$ & $0.57(0.10-2.81)$ & $1.37(0.70-2.65)$ \\
\hline & Class 3 & $1.06(0.41-2.74)$ & $0.71(0.18-2.89)$ & $0.97(0.50-1.89)$ \\
\hline & Class 4 & $1.55(0.62-2.69)$ & $0.44(0.07-2.33)$ & $1.32(0.63-2.62)$ \\
\hline & Class 5 & $2.40(0.91-6.30)$ & $2.52(0.37-6.43)$ & $0.82(0.39-1.72)$ \\
\hline \multirow[t]{2}{*}{ Alcohol consumption } & No & 1 & 1 & 1 \\
\hline & Yes & $1.22(0.42-3.55)$ & $1.69(0.43-6.59)$ & $1.78(0.94-3.37)$ \\
\hline \multirow[t]{2}{*}{ Body mass index } & $<25 \mathrm{~kg} \cdot \mathrm{m}^{2}$ & 1 & 1 & 1 \\
\hline & $\geq 25 \mathrm{~kg} \cdot \mathrm{m}^{2}$ & $1.38(0.74-2.59)$ & $0.65(0.23-1.87)$ & $2.06(1.27-3.34)$ \\
\hline \multirow[t]{2}{*}{ Calorie intake } & $<2500 \mathrm{kcal}$ per day & 1 & 1 & 1 \\
\hline & $\geq 2500 \mathrm{kcal}$ per day & $1.35(0.69-2.63)$ & $0.30(0.11-0.85)$ & $0.68(0.39-1.19)$ \\
\hline \multirow[t]{3}{*}{ Physical activity } & Low & 1 & 1 & 1 \\
\hline & Moderate & $0.72(0.38-1.34)$ & $1.42(0.48-4.18)$ & $0.63(0.38-1.03)$ \\
\hline & Vigorous & $0.71(0.31-1.60)$ & $0.97(0.35-3.70)$ & $0.45(0.26-0.78$ \\
\hline \multirow[t]{2}{*}{ Diabetes } & No & 1 & 1 & 1 \\
\hline & Yes & $1.26(0.53-2.98)$ & $4.48(1.16-17.20)$ & $2.28(1.32-32.92)$ \\
\hline \multirow[t]{2}{*}{ Hyperlipidemia } & No & 1 & 1 & 1 \\
\hline & Yes & $1.55(0.84-2.67)$ & $1.41(0.53-3.73)$ & $1.65(1.1-2.59)$ \\
\hline \multirow[t]{2}{*}{ Hypertension } & No & 1 & 1 & 1 \\
\hline & Yes & $15.75(8.88-15.76)$ & $17.44(6.38-47.71)$ & $7.59(4.82-11.68)$ \\
\hline
\end{tabular}

*Adjusted in terms of age, sex, socio-economic status, alcohol use, body mass index, physical activity, diabetes, hypertension, lipid disorder 


\section{Discussion}

Smoking was significantly association with the risk factors of CVD and the association between smoking and the risk factors of CVD was significantly differ across different levels of smoking. In diabetic patients, hypertension and lipid disorder, smoking can increase odds of CVD. In the other hand, vigorous physical activity and a normal body mass index are among the factors which can reduce CVD odds in smokers.

According to the present study, light and moderate smokers (0-19 cigarettes a day) had a greater CVD risk compared to heavy smokers ( $\geq 20$ cigarettes a day). Furthermore, for light, moderate, and heavy smokers, hypertension was an important factor of CVD. A prospective study with a 15-year follow-up maintained that there is a significant association between the simultaneity of smoking and hypertension and a risk of CVD. Also, a study by Jibin Tan et al. showed that in participants with hypertension, the risk of death was slightly higher for individuals who smoked 0-19 packs of cigarettes a year, than those who smoked 20 packs per year (2). As reported by a prospective study, the CVD-induced risk of death is higher in individuals who smoke 0.1 to 9 packs of cigarettes per year, compared to those who smoked 10 to 19 and $\geq 20$ packs of cigarettes per year (16), which is similar to our results.

Diabetic individuals are at a higher CVD risk and the associated mortality compared to non-diabetic individuals $(17,18)$, As smoking is a reported risk factor of diabetes and CVD $(19,20)$, the coexistence of smoking and diabetes can increase the risk of CVD (20). As seen in the findings of the present study, for current smokers, the CVD prevalence was $33 \%$ in diabetic and $18 \%$ in non-diabetic participants. Similarly, for light, moderate, and heavy smokers, the risk of CVD was higher in diabetic rather than non-diabetic participants.

An analysis of smoking subgroups showed that the risk of CVD in participants with diabetes and hypertension was higher in former smokers than current smokers, which conforms to the results of the study by Mi Hee Cho (20). An acceptable justification for this finding requires prospective studies entailing all the aspects of the participants' lives, including lifestyle, degrees of stress and anxiety before and after quitting smoking, nutrition, and body composition.

In the present study, the risk of CVD in current smokers with a lipid disorder was higher compared to participants with normal lipid profiles. A study by Parsa et al. reported that CVD-induced deaths in smokers with desirable blood cholesterol was considerably higher than nonsmokers (21). Based on the foregone finding, smoking, not only can cause cardiovascular diseases as an independent risk factor, but also, combined with other risk factors, like lipid disorders, can increase CVD risks. The approval of the foregone shall require further prospective studies and studies investigating the interactions of smoking.

Considering the fact that the sample size was not identical in the three subgroups of smoking, to ensure the validity of odds ratio results, the authors conducted the analysis on 1000 random samples from the never smoker population, which revealed that the population difference was ineffective. One of the limitations of the present study is its cross-sectional nature, rendering it unable to show the causal relations between the variables. A large sample size was one of the strengths of the present study. Having been obtained from a prospective study, the results are highly reliable. Another point of strength of the present study is the adjustment of most of the recognized confounding factors including age, sex, physical activity, socio-economic status, body mass index, energy intake, and chronic diseases.

\section{Conclusion}

Smoking was significantly association with the risk factors of CVD and the association between smoking and the risk factors of CVD was significantly differ across different levels of smoking. In diabetic patients, hypertension and lipid disorder, smoking can increase odds of CVD. Instead, vigorous physical activity and a normal body mass index are among the factors which can reduce CVD odds in smokers.

Smoking is a modifiable risk factor for chronic diseases, including cardiovascular diseases, correcting it, therefore, can to a large extent help prevent and control cardiovascular diseases. Quitting or reducing smoking will lessen the CVD-induced burden and mortality.

\section{Declarations}

\section{Ethics approval and consent to participate:}

The research was approved by the ethics committee of Kermanshah University of Medical Sciences (KUMS.REC.1394.318). All participants gave written informed consent to participate in the study.

\section{Consent for publication:}

Not applicable. 
Availability of data and materials:

No specific funding was received from any bodies in the public.

\section{Competing interests:}

The authors declare that they have no competing interests.

Funding:

No specific funding was received from any bodies in the public. The research was registered (No: 92472) at the Research and Technology Deputy.

\section{Author Contributions:}

Conceptualization: Pasdar Y, Hamzeh B, Najafi N

Data curation: Darbandi M, Safari Faramani R

Formal analysis: Safari Faramani R, Najafi N

Writing - original draft: Darbandi M

Writing - review \& editing: Pasdar Y, Hamzeh B, Shakiba E

\section{Acknowledgements}

RaNCD cohort study is a part of PERSIAN national cohort and we would like to thank professor Reza Menkzadeh Deputy of Research and Technology at the Ministry of health and Medical Education of Iran and Director of the PERSIAN cohort.

\section{References}

1. https://www.who.int/news-room/fact-sheets/detail/the-top-10-causes-of-death. 24 May 2018.

2. Tan J, Zhang X, Wang W, Yin P, Guo X, Zhou M. Smoking, blood pressure, and cardiovascular disease mortality in a large cohort of Chinese men with 15 Years follow-up. International journal of environmental research public health. 2018;15(5):1026. doi:10.3390/ijerph15051026.

3. Gakidou E, Afshin A, Abajobir AA, Abate KH, Abbafati C, Abbas KM, et al. Global, regional, and national comparative risk assessment of 84 behavioural, environmental and occupational, and metabolic risks or clusters of risks, 1990-2016: a systematic analysis for the Global Burden of Disease Study 2016. The Lancet. 2017;390(10100):1345-422.doi: 10.016/S0140-6736(17)32366-8.

4. https://www.who.int/news-room/fact-sheets/detail/cardiovascular-diseases-(cvds). 17 May 2017.

5. Ndindjock R, Gedeon J, Mendis S, Paccaud F, Bovet P. Potential impact of single-risk-factor versus total risk management for the prevention of cardiovascular events in Seychelles. Bulletin of the World Health Organization. 2011;89:286-95.doi: 10.2471/BLT.10.082370. .

6. Yusuf S, Hawken S, Ôunpuu S, Dans T, Avezum A, Lanas F, et al. Effect of potentially modifiable risk factors associated with myocardial infarction in 52 countries (the INTERHEART study): case-control study. lancet. 2004;364(9438):937-52.doi: 10.1016/S01406736(04)17018-9.

7. Liu S, Zhang M, Yang L, Li Y, Wang L, Huang Z, et al. Prevalence and patterns of tobacco smoking among Chinese adult men and women: findings of the 2010 national smoking survey. J Epidemiol Community Health. 2017;71(2):154-61.doi: 10.1136/jech-2016-207805. .

8. Cho MH, Lee K, Park SM, Chang J, Choi S, Kim K, et al. Effects of smoking habit change on all-cause mortality and cardiovascular diseases among patients with newly diagnosed diabetes in Korea. J Scientific reports. 2018;8(1):5316.

9. Lee PN, Forey BA, Thornton AJ, Coombs KJ. The relationship of cigarette smoking in Japan to lung cancer, COPD, ischemic heart disease and stroke: A systematic review. J FResearch. 2018;7(204): doi: 10.12688/f1000research.4002.1.

10. Honjo K, Iso H, Tsugane S, Tamakoshi A, Satoh H, Tajima K, et al. The effects of smoking and smoking cessation on mortality from cardiovascular disease among Japanese: pooled analysis of three large-scale cohort studies in Japan. J Tobacco Control. 2010;19(1):507.doi: 10.1136/tc.2009.029751. .

11. Moosazadeh M, Ziaaddini H, Mirzazadeh A, Ashrafi-Asgarabad A, Haghdoost AA. Meta-analysis of smoking prevalence in Iran. J Addiction health. 2013;5(3-4):140. 
12. Meysamie A, Ghaletaki R, Haghazali M, Asgari F, Rashidi A, Khalilzadeh O, et al. Pattern of tobacco use among the Iranian adult population: results of the national Survey of Risk Factors of Non-Communicable Diseases (SuRFNCD-2007). J Tobacco control. 2010;19(2):125-8.doi: 10.1136/tc.2009.030759.

13. Rezaei S, Sari AA, Arab M, Majdzadeh R, Poorasl AM. Economic burden of smoking: a systematic review of direct and indirect costs. J Medical journal of the Islamic Republic of Iran. 2016;30:397.

14. Poustchi H, Eghtesad S, Kamangar F, Etemadi A, Keshtkar A-A, Hekmatdoost A, et al. Prospective epidemiological research studies in Iran (the PERSIAN Cohort Study): rationale, objectives, and design. American journal of epidemiology. 2017;187(4):647-55.doi: 10.1093/aje/kwx314.

15. Pasdar Y, Najafi F, Moradinazar M, Shakiba E, Karim H, Hamzeh B, et al. Cohort profile: Ravansar Non-Communicable Disease cohort study: the first cohort study in a Kurdish population. J International journal of epidemiology. 2019;48(3):682-83.doi: 10.1093/ije/dyy296.

16. Ge Z, Hao Y, Cao J, Li J, Chen J, Huang J, et al. Does cigarette smoking exacerbate the effect of blood pressure on the risk of cardiovascular and all-cause mortality among hypertensive patients? Journal of hypertension. 2012;30(12):2307-13.doi: 10.1097/HJH.0b013e328359aa1f.

17. Shah AD, Langenberg C, Rapsomaniki E, Denaxas S, Pujades-Rodriguez M, Gale CP, et al. Type 2 diabetes and incidence of cardiovascular diseases: a cohort study in 1. 9 million people. J The lancet Diabetes endocrinology. 2015;3(2):105-13.doi: 10.1016/S22138587(14)70219-0.

18. Yeh H-C, Duncan BB, Schmidt MI, Wang N-Y, Brancati FL. Smoking, smoking cessation, and risk for type 2 diabetes mellitus: a cohort study. J Annals of internal medicine. 2010;152(1):10-7.doi: .7326/0003-4819-152-1-201001050-00005.

19. Akter S, Okazaki H, Kuwahara K, Miyamoto T, Murakami T, Shimizu C, et al. Smoking, smoking cessation, and the risk of type 2 diabetes among Japanese adults: Japan Epidemiology Collaboration on Occupational Health Study. J PLoS One. 2015;10(7):e0132166.doi: 10.1371/journal.pone..

20. Cho MH, Lee K, Park SM, Chang J, Choi S, Kim K, et al. Effects of smoking habit change on all-cause mortality and cardiovascular diseases among patients with newly diagnosed diabetes in Korea. J Scientific reports. 2018;8(1):5316.doi: 10.1038/s41598-018-23729-0.

21. Parsa N, Taravatmanesh S, Trevisan M, Zaheri PM. The Mutual Impact of Smoking and Low Cholesterol on All-Cause, NonCardiovascular, and Cardiovascular Mortalities in Males. J American journal of men's health. 2018;12(6):2128-35.doi: $10.1177 / 1557988318795790$. 